\title{
Development of a combined machining method using electrorheological fluids for EDM
}

\author{
Y.Y. Tsai*, C.H. Tseng, C.K. Chang \\ Department of Mechanical Engineering, National Taiwan University, No. 1, Sec. 4, Roosevelt Road, Taipei 10617, Taiwan
}

\section{A R T I C L E I N F O}

\section{Keywords:}

Electrical discharge machining

(EDM)

Electrorheology (ER)

Polishing

Combined method

\begin{abstract}
A B S T R A C T
The objective of this study is to develop a new combined technology of electrical discharge machining (EDM) with polishing by using electrorheological (ER) fluid as working fluid. The surface of the work-piece after EDM has a recast layer with many micro-craters and cracks. Therefore, the polishing process is usually required after EDM for the molds applied on computer, communication and consumer electronics (3C) industries. In the study, we proposed a novel method of EDM that used ER fluid instead of water or oil and employed fine abrasive grits to carry out the combined process of EDM and polishing. The effect of this new electromechanical process combining EDM and polishing was investigated. The experimental results demonstrate EDM process still can perform in the ER fluid and polishing process can be surely performed after adding the alumina abrasives. We have a good performance to obtain surface roughness of $R_{a} 0.08-0.06 \mu \mathrm{m}$ when using alumina abrasives of $0.3 \mu \mathrm{m}$ and discharge capacity of $0.01 \mu \mathrm{F}$ in the proposed method.
\end{abstract}

(c) 2008 Elsevier B.V. All rights reserved.

\section{Introduction}

The requirements of molds and dies for $3 \mathrm{C}$ industry are not only the smaller size but also the higher precision and the finer surface roughness. Electrical discharge machining (EDM) process has excellent performance on machining of hard material, which is an important method for mold industry. However, the surface after EDM has recast layer with many craters and micro-cracks. Polishing is a post-process after EDM and usually essential to obtain mirror-like surface. Except for cost of time and money, polishing process is also difficult to perform specially for small size of mold.

In this study, we proposed a novel method of EDM that used electrorheological (ER) fluid instead of water or oil and employed abrasive to carry out polishing process as shown in Fig. 1. Since there is very strong electric field between workpiece and electrode before discharge occurrence, it is possible to induce the electric field to assist polishing in EDM. For interval time of discharge pulse, ER particles will become fibrous chains as the result of polarization. And then the fibrous chains seem to be working as polishing brushes dragging abrasive to carry out polishing process. This new developed method will combine EDM and polishing in one process. It would save time and make the economical efficiency much better.

The electrorheological fluid was also called Winslow fluid which was discovered by Winslow (1949). It consisted of dielectric particles in the insulating fluid. These dielectric particles are polarized easily under high electric field strength and then the ER fluid will transform into a plastic flow. If the electric field were stronger, even the ER fluid will be solidified (Vinogradov et al., 1986). The viscosity of the ER fluid is varied due to the electric field. It is a Newtonian fluid without the electric field applied but it becomes the Bingham plastic flow when applying the electric field (Bonnecaze and Brady, 1992). Fig. 2 shows the mechanism for the electrorheological behavior.

Kuriyagawa et al. (2002) firstly utilized ER fluid for the polishing of optical micro-lenses. They used the rotary metal tool

\footnotetext{
* Corresponding author. Tel.: +886 2 33662714; fax: +886 223631755.

E-mail addresses: yytsai@ntu.edu.tw (Y.Y. Tsai), b89502117@ntu.edu.tw (C.H. Tseng), r95522719@ntu.edu.tw (C.K. Chang). 0924-0136/\$ - see front matter @ 2008 Elsevier B.V. All rights reserved.
} doi:10.1016/j.jmatprotec.2007.11.150 

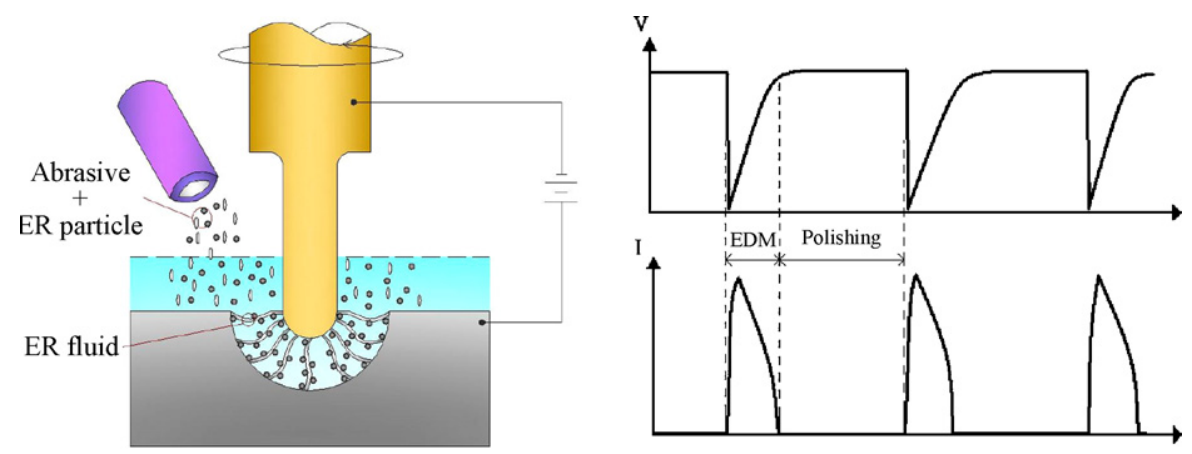

Fig. 1 - Schematic diagram of the proposed method using ER fluid and abrasive gifts.
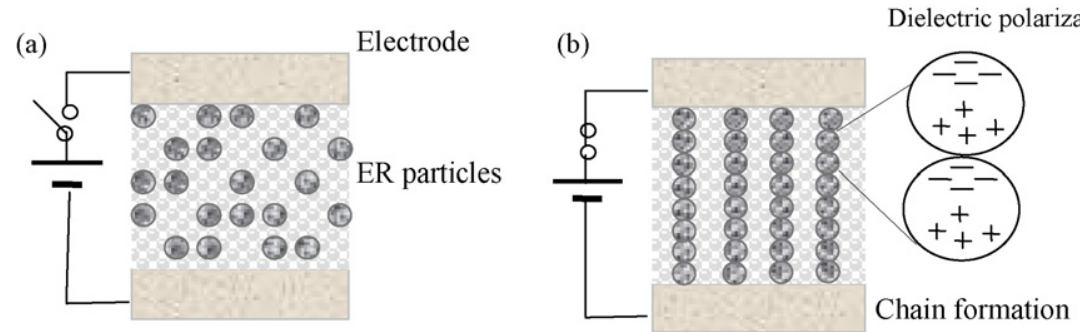

Fig. 2 - Schematic diagram of the mechanism for the electrorheological behavior: (a) without electric field and (b) with strong electric field.

and plate covering the lens to build the electric field. The space of electric field was full of the abrasive and the ER fluid. The abrasives are held softly at the tip of the tool to polish the small parts.

Kim et al. (2003) discussed the dipolar interaction force and the translational force along the electric field on the ER particles to understand the process of ER fluid-assisted polishing.

\section{Experimental}

\subsection{Experimental procedure}

This novel method is a new try-out and the performance of EDM in ER fluid with suspending starch powder in silicone oil was examined firstly. The influences of starch concen-

Table 1 - Experimental parameters

\begin{tabular}{ll} 
Working factor & \multicolumn{1}{c}{ Working condition } \\
\hline Electrode & Copper \\
Work-piece & Stainless steel (SUS304) \\
Abrasive & Alumina powder $\left(\mathrm{Al}_{2} \mathrm{O}_{3}\right)$ \\
Working fluid & Conventional EDM oil, ER fluid \\
& with different cons. \\
ER particle & Starch \\
Particle size $(\mu \mathrm{m})$ & $17.6(-325$ mesh) $, 1,0.3$ \\
Concentration of abrasive $(\%)$ & $0,5,10,20,30$ \\
Concentration of starch $(\%)$ & $0,10,20,30,40,60$ \\
Discharge voltage $(\mathrm{V})$ & 100,250 \\
Capacitance $(\mu \mathrm{F})$ & $0.068,0.01$ \\
Rotational speed $(\mathrm{rpm})$ & 2000 \\
\end{tabular}

tration on pulse waveform and discharge frequency were discussed. Then, adding $\mathrm{Al}_{2} \mathrm{O}_{3}$ abrasive in ER fluid induces polishing process to EDM in ER fluid. The effect of this new electromechanical process combining EDM and polishing was investigated. We especially tried to discuss the surface roughness in this combined machining process.

\subsection{Experimental apparatus}

The abrasive was $\mathrm{Al}_{2} \mathrm{O}_{3}$ with the diameters of $17.6 \mu \mathrm{m}, 1 \mu \mathrm{m}$, and $0.3 \mu \mathrm{m}$. The working fluid was composed of different con-

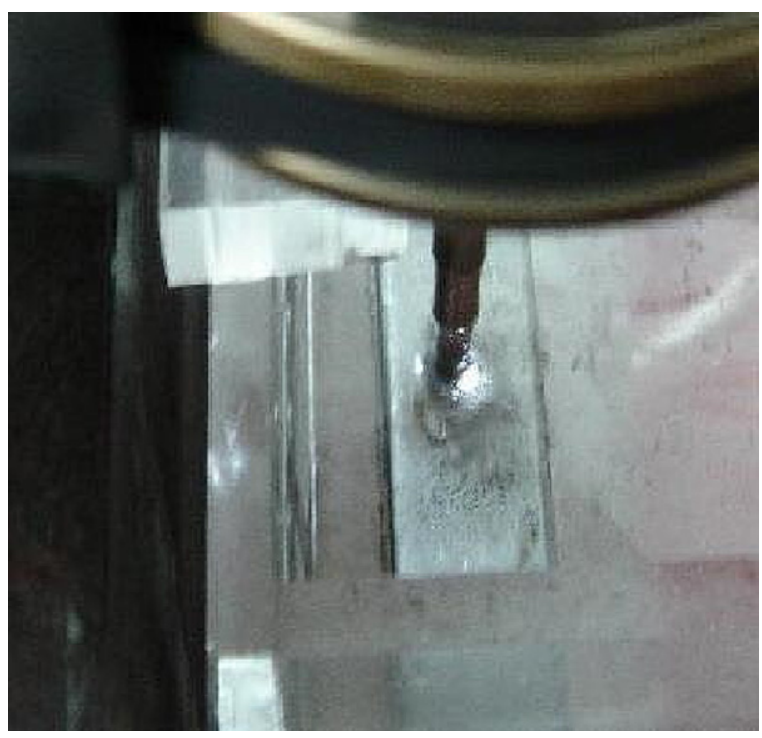

Fig. 3 - Discharge spark when EDM in ER fluid. 
(a)

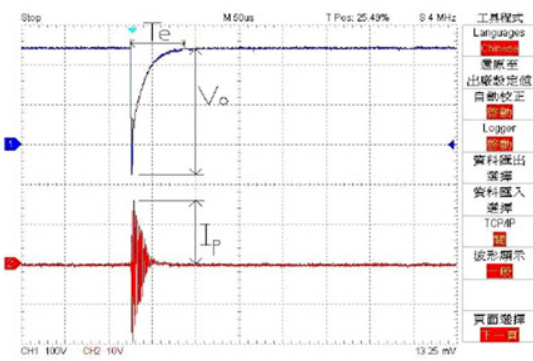

(d)

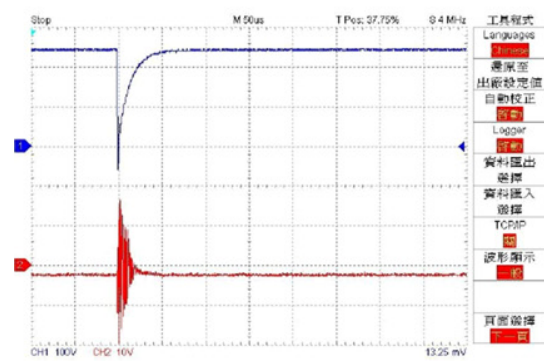

(b)

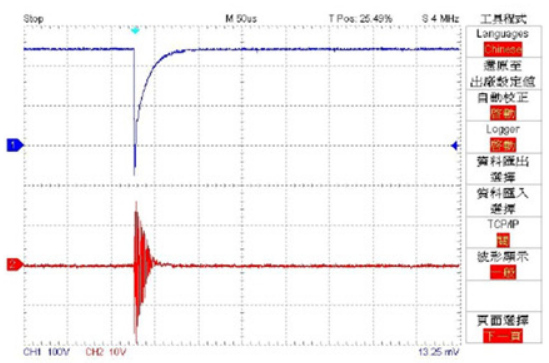

(e)

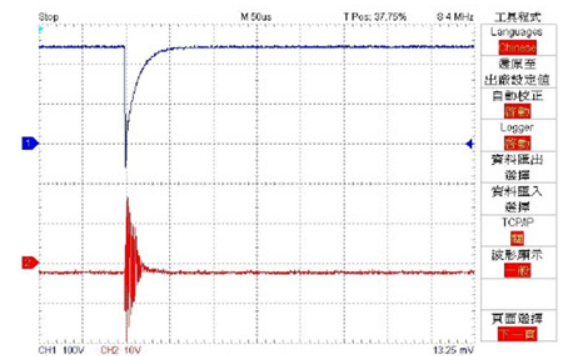

(c)

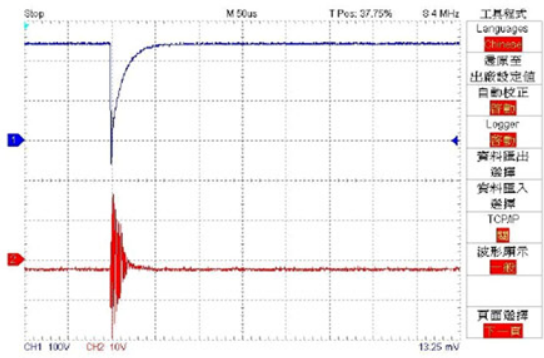

(f)

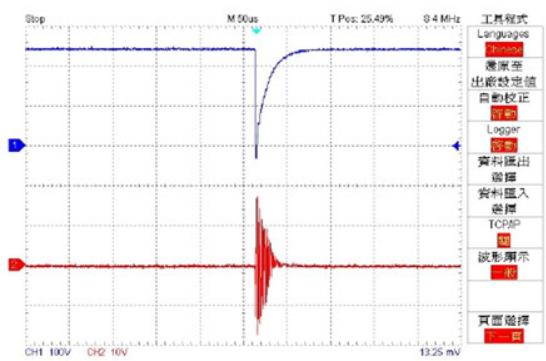

Fig. 4 - Voltage and current waveforms in the different concentrations of ER fluid: (a) EDM oil; (b) silicon oil; (c) 10\% starch; (d) $20 \%$ starch; (e) $40 \%$ starch; (f) $60 \%$ starch.

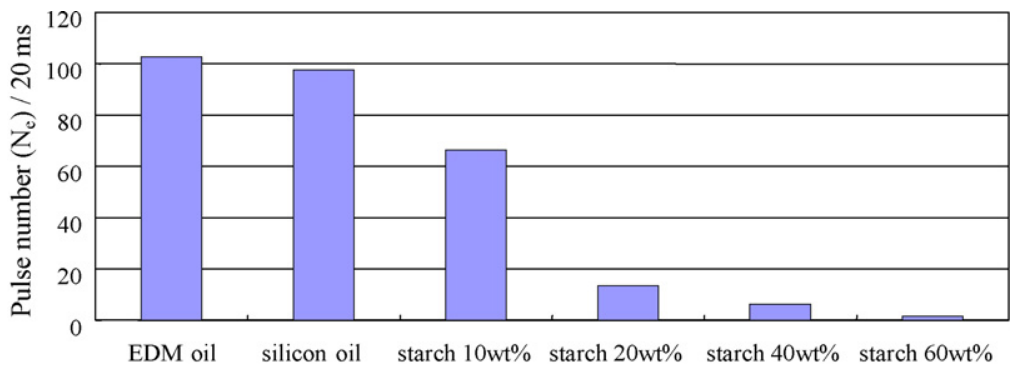

Fig. 5 - The discharging pulse number for different working fluid.

centrations of $\mathrm{Al}_{2} \mathrm{O}_{3}$ powders and starch. The gap between electrode and work-piece was kept below $50 \mu \mathrm{m}$. The copper was used as the cathode which was $1 \mathrm{~mm}$ in diameter with rotational speed of $2000 \mathrm{rpm}$, and stainless steel was used as work-piece in all experiments. The discharge voltage of $100 \mathrm{~V}$ and $250 \mathrm{~V}$ are used. The discharge capacitance had $0.068 \mu \mathrm{F}$ and $0.01 \mu \mathrm{F}$. The parameters used in the experiments were listed in Table 1.

\section{Experimental results and discussion}

\subsection{Performance of EDM in ER fluid}

\subsubsection{Examination of discharging waveform}

It was easy to find the occurrence of discharge spark during the process of EDM in ER fluid as shown in Fig. 3, which seems
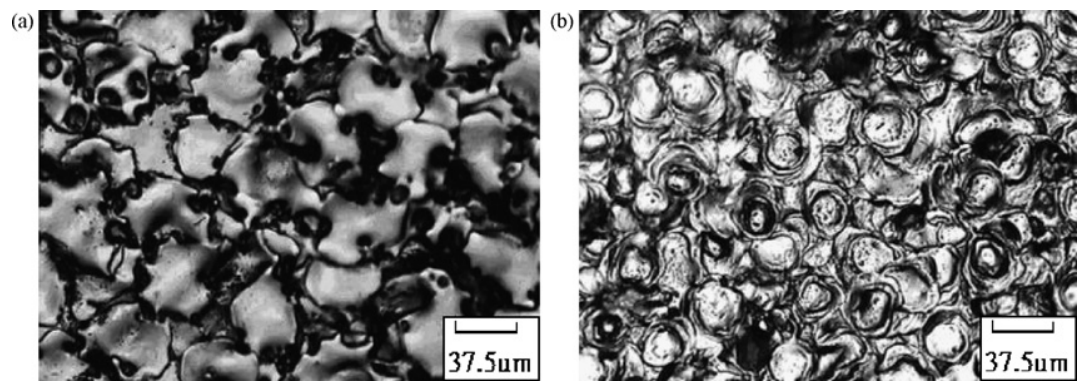

Fig. 6 - The machined surface using conventional EDM oil and pure silicon oil under the discharge capacitance of $0.068 \mu \mathrm{F}$ : (a) EDM oil, $R_{\mathrm{a}}=1.08 \mu \mathrm{m}$ and (b) silicon oil, $R_{\mathrm{a}}=1.36 \mu \mathrm{m}$. 
to be the same as general EDM in oil. An oscilloscope was used to monitor and record the pulse waveform of discharge. Fig. 4 shows pulse waveform with the constant capacitance of $0.068 \mu \mathrm{F}$. It is obvious to find a discharge pulse as the result of breaking down when the gap voltage drops $\left(V_{0}\right)$ instantaneously. By comparison of the pulse waveform in different working fluids, the voltage drops $\left(V_{0}\right)$, peak current $\left(I_{p}\right)$ and time duration $\left(\mathrm{T}_{\mathrm{e}}\right)$ were almost the same. This pointed out the pulse waveform, the voltage drop and peak current are basically not affected by ER fluid.

\subsubsection{Discharge frequency}

Discharge spark appears when electric voltage drops instantaneously and electric current increases suddenly. The number of discharge pulse can be viewed through monitor. Fig. 5 shows the number of discharge pulse $\left(N_{e}\right)$ during the period of $20 \mathrm{~ms}$

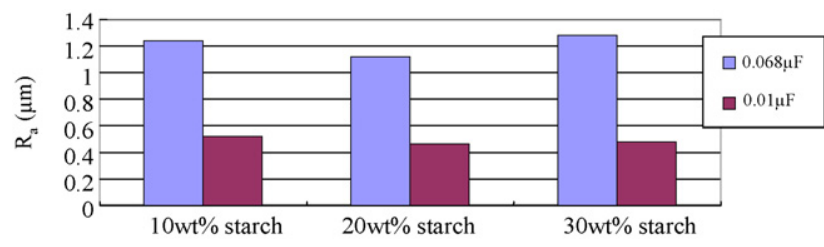

Fig. 7 - The $R_{a}$ values of different concentration of ER fluid.

$\left(10^{-3} \mathrm{~s}\right)$ for various working fluids. The discharge pulse number is maxima when using general EDM oil. Pure silicon oil is in the second place and $\mathrm{N}_{\mathrm{e}}$ decreased gradually with the increase of starch concentration. ER fluid will become very sticky and the probability of discharging is reduced when the starch concentration is higher. Besides, the discharging spark would appear
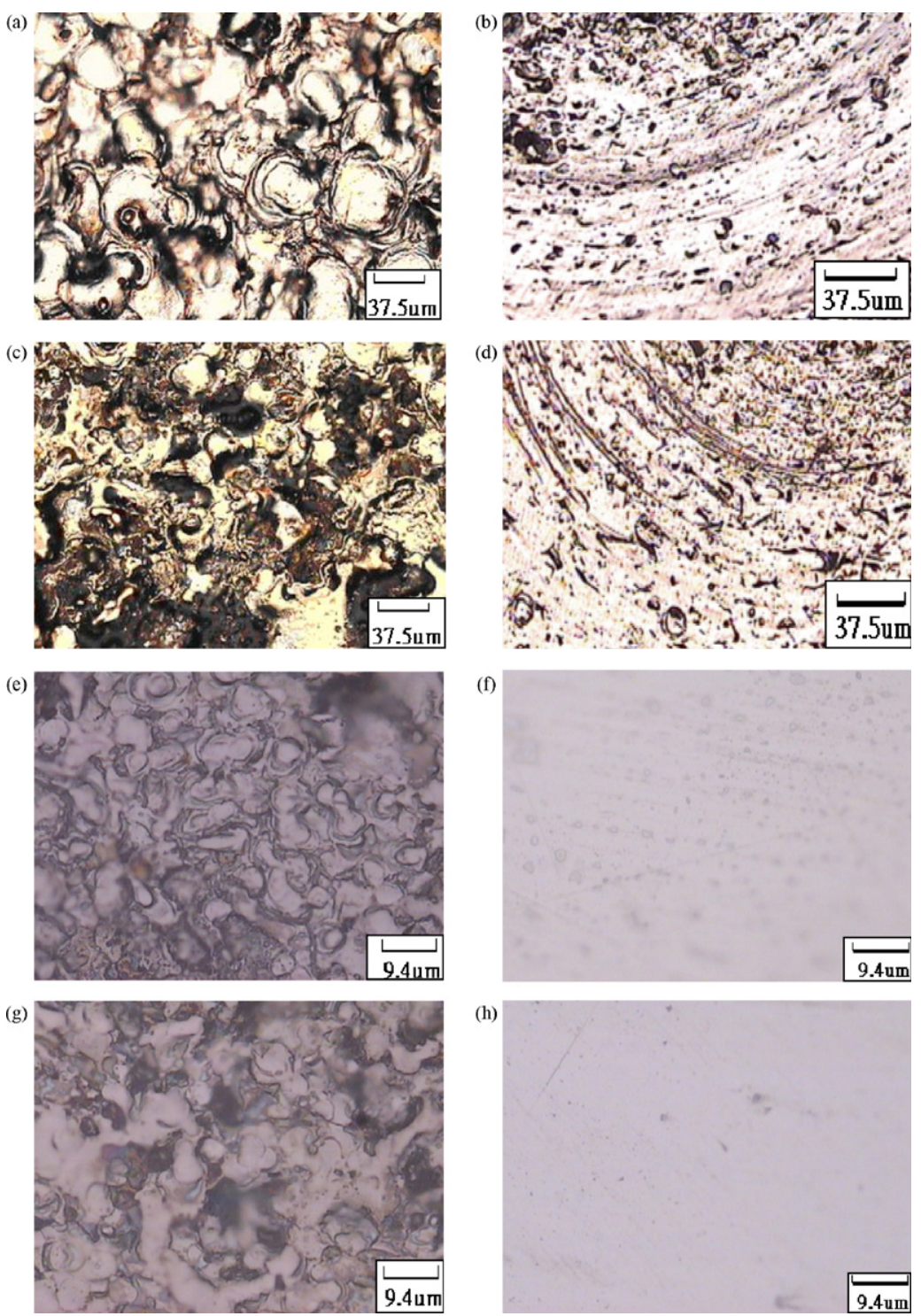

Fig. 8 - The machined surface for different concentrations of starch and abrasive $\mathrm{Al}_{2} \mathrm{O}_{3}$ under the discharge capacitance of $0.068 \mu \mathrm{F}$ and $0.01 \mu \mathrm{F}$ : (a) $10 \mathrm{wt} . \%$ starch without $\mathrm{Al}_{2} \mathrm{O}_{3} \mathrm{R}_{\mathrm{a}}=1.24 \mu \mathrm{m} \mathrm{C}=0.068 \mu \mathrm{F}$; (b) $10 \mathrm{wt} \%$ starch $-10 \mathrm{wt} . \% \mathrm{Al}_{2} \mathrm{O}_{3} \mathrm{R}_{\mathrm{a}}=0.26 \mu \mathrm{m}$ $\mathrm{C}=0.068 \mu \mathrm{F}$; (c) $20 \mathrm{wt} . \%$ starch without $\mathrm{Al}_{2} \mathrm{O}_{3} \mathrm{R}_{\mathrm{a}}=1.12 \mu \mathrm{m} \mathrm{C}=0.068 \mu \mathrm{F}$; (d) $20 \mathrm{wt}$. $\%$ starch-10 wt. $\% \mathrm{Al}_{2} \mathrm{O}_{3} \mathrm{R}_{\mathrm{a}}=0.14 \mu \mathrm{m}$ $\mathrm{C}=0.068 \mu \mathrm{F}$; (e) $10 \mathrm{wt} . \%$ starch without $\mathrm{Al}_{2} \mathrm{O}_{3} R_{\mathrm{a}}=0.52 \mu \mathrm{m} \mathrm{C}=0.01 \mu \mathrm{F}$; (f) 10 wt. $\%$ starch-10 wt. $\% \mathrm{Al}_{2} \mathrm{O}_{3} R_{\mathrm{a}}=0.06 \mu \mathrm{m} \mathrm{C}=0.01 \mu \mathrm{F}$; (g) 20 wt. $\%$ starch without $\mathrm{Al}_{2} \mathrm{O}_{3} R_{\mathrm{a}}=0.46 \mu \mathrm{m} \mathrm{C}=0.01 \mu \mathrm{F}$; (h) 20 wt\% starch-10 wt. $\% \mathrm{Al}_{2} \mathrm{O}_{3} \mathrm{R}_{\mathrm{a}}=0.08 \mu \mathrm{m} \mathrm{C}=0.01 \mu \mathrm{F}$. 
hardly when using higher concentration of alumina powder in ER fluid. This result leaded to less EDM but more polishing would be carried out with adding $\mathrm{Al}_{2} \mathrm{O}_{3}$ abrasive.

\subsection{Polishing effect}

\subsubsection{Surface roughness of EDM in ER fluid}

Fig. 6 shows the machined surface of EDM when using conventional EDM oil and pure silicon oil under the discharge capacitance of $0.068 \mu \mathrm{F}$. The discharge craters were still found apparently and the roughness of pure silicone oil was worse than the one of EDM oil. Fig. 7 shows the investigation results of surface roughness $\left(R_{\mathrm{a}}\right)$ for different starch concentrations from $10 \%$ to $30 \%$ when the discharge capacitance of $0.01 \mu \mathrm{F}$ and $0.68 \mu \mathrm{F}$. As the figure indicates, starch concentration has not strong influence on surface roughness of EDM in comparison with the discharge capacitance. In other words, the discharge capacitance is the decisive factor of surface roughness, which determines the energy of discharge pulse.

\subsubsection{Surface roughness of EDM in ER fluid with adding $\mathrm{Al}_{2} \mathrm{O}_{3}$ powders}

In this section, the abrasive powder was added in ER fluid composed by starch and polishing effect was investigated. Fig. 8 shows the machined surface using ER fluid and the abrasive $\mathrm{Al}_{2} \mathrm{O}_{3}$ under the discharge capacitance of $0.068 \mu \mathrm{F}$ and $0.01 \mu \mathrm{F}$. In the result, using ER fluid by adding the $\mathrm{Al}_{2} \mathrm{O}_{3}$ abrasive of $0.3 \mu \mathrm{m}$, there was no crater found and submicron $R_{a}$ obtained. The roughness under the discharge capacitance of $0.068 \mu \mathrm{F}$ was improved from $R_{\mathrm{a}} 1.24 \mu \mathrm{m}$ to $R_{\mathrm{a}} 0.26 \mu \mathrm{m}$ for $10 \%$ starch concentration, and from $R_{a} 1.12 \mu \mathrm{m}$ to $R_{a} 0.14 \mu \mathrm{m}$ for $20 \%$ starch concentration. Mirror-like surface can be obtained when using the smaller capacitance of $0.01 \mu \mathrm{F}$. The roughness under the discharge capacitance of $0.01 \mu \mathrm{F}$ was improved to $R_{a}$ $0.06 \mu \mathrm{m}$ and $\mathrm{R}_{\mathrm{a}} 0.08 \mu \mathrm{m}$ after adding $\mathrm{Al}_{2} \mathrm{O}_{3}$ abrasives of $0.3 \mu \mathrm{m}$ in the ER fluid of $10 \%$ and $20 \%$ starch concentration. It is clear that polishing process is surely performed to obtain the surface roughness of nanometer order.

\section{Conclusion}

In this study, we used the ER fluid and alumina powders to develop the new electromechanical technology combin- ing EDM and polishing. The starch particles gather and become the fibrous chains due to polarization when the electrical field was applied in the ER fluid. Then the fibrous chains provide polishing brushes dragging abrasive powders to carry out polishing. The main results are summarized as follows:

1. The results demonstrate EDM process still can be performed in the ER fluid. The waveform of single discharging pulse is almost the same whenever starch concentration was. However discharge frequency, the pulse number during the constant period decreased with increasing the concentration of starch and alumina. Using more starch particles and alumina powders would reduce discharge efficiency but make longer polishing process time.

2. Only using ER fluid of starch particles without abrasive $\mathrm{Al}_{2} \mathrm{O}_{3}$ as working fluid, the roughness would be improved a little. In that case, the discharge capacitance is the decisive factor of surface roughness, which determines the energy of discharge pulse.

3. Adding the abrasive in the ER fluid surely has the polishing effect to improve the surface roughness. The roughness by using the ER fluid with alumina powder of $0.3 \mu \mathrm{m}$ was improved to $R_{a} 0.06 \mu \mathrm{m}$ for discharge capacitance of $0.01 \mu \mathrm{F}$, and no crater was found.

\section{REFERENCES}

Bonnecaze, R.T., Brady, J.F., 1992. Dynamic simulation of an electrorheological fluid. J. Chem. Phys. 96, 2183-2202.

Kim, W.B., Lee, S.J., Kim, Y.J., Lee, E.S., 2003. The electromechanical principle of electrorheological fluid-assisted polishing. Int. J. Mach. Tools Manuf. 43, 81-88.

Kuriyagawa, T., Saeki, M., Syoji, K., 2002. Electrorheological fluid-assisted ultra-precision polishing for small three-dimensional parts. Precis. Eng. 26, 370-380.

Vinogradov, G.V., Shul'man, Z.P., Yanovskii, Yu.G., Barancheeva, V.V., Korobko, E.V., Bukovich, I.V., 1986. Viscoelastic behavior of electrorheological suspensions. J. Eng. Phys. 50, 429-432.

Winslow, W.M., 1949. Induced vibration of suspensions. J. Appl. Phys. 20, 1137-1140. 